Hoken Butsuri, 24, 25 30 (1989)

\title{
TECHNICAL
}

\section{Comparison of Sensitivity between Two Methods (a Decay Method and a Build-up and Decay Method) in Monitoring of Individual Radon Daughters}

\author{
Hiroshi KoJIMA ${ }^{*, * 1}$ and Siro AbE ${ }^{* *, * 2}$
}

(Received November 26, 1987)

(Accepted September 7, 1988)

\begin{abstract}
A radon daughter monitor with a build-up and decay method (B.D.R.D. monitor) was developed to investigate the behavior of short-lived radon daughters indoors and outdoors. The monitor was available for long term continuous measurements with simple maintenance every a month.

The sensitivity of the new monitor was compared with that of the monitor with a decay method (D.R.D. monitor), which has been called Thomas method. As the results, it was found that the B.D.R.D. monitor is more better than that of the D.R.D. monitor in assessment of RaA having the shortest life time among radon daughters. It was found, also, that the plateout effect of radon daughter gave slight and unavoidable errors to the B.D.R.D. monitor through the process of both the counting loss and the enhancement of background level. It was concluded that even if the B.D.R.D. monitor had those disadvantages it was very useful instrument to measure individual radon daughters in the natural environment.
\end{abstract}

KEY WORDS: radon daughter, individual, monitoring, sensitivity, comparison, plateout, decay method, buildup-decay method

\section{INTRODUCTION}

It has generally been considered that radon and the short-lived decay products may become a health hazard when exposed to the respiratory system. Therefore, attention of many researchers has been focused on the measurements of those nuclides indoors and outdoors. Up to the present, many studies have been carried out through the measurements of radioactive radon gas among the nuclides. On the other hand, there are a few studies on individual concentration of radon daughters which are including two alpha emitters

*览島 紘, ** 阿部史朗

*1 Science University of Tokyo, Noda, Chiba 278. 東京理科大学理工学部; 野田市山崎 2641 (T278)

*2 National Institute of Radiological Science, Chiba 260.

放射線医学総合研究所; 千葉市穴川 4-9-1 (下260)
( $\mathrm{RaA}$ and $\mathrm{RaC}^{\prime}$ ) and which have direct influence on a health hazard. The main reason for this may be due to a lack of specific instruments for radon daughters applicable to the measurements in very low concentration like natural environments.

Measurements of individual radon daughters have usually been measured by a means of a filter method. In this method radon daughters in the air are sampled on a filter paper and are counted in a three counting way. The concentrations of individual radon daughters ( $\mathrm{RaA}, \mathrm{RaB}$ and $\mathrm{RaC}$ ) are evaluated from the three counting values by use of simultaneous equations for the theoretical build-up or decay characteristics. In general, owing to low background values, the alpha activities from radon daughters are counted.

The filter methods, which have been studied up to the present, are divided into four groups accord- 
ing to two categories. The counting of alpha rays is performed by a spectroscopic way or a gross counting way and the individual radon daughter concentration is calculated by the equations expressing a decay or both build-up and decay characteristics.

In the gross counting way, therefore, there are two methods. One is the method based on the decay characteristics, which was developed by Tsivoglou et al. ${ }^{1}$ and Thomas, ${ }^{2)}$ where three countings were done only after the end of sampling period. The other is the method based on build-up and decay characteristics, which was developed by $\mathrm{CLIFF}^{3}{ }^{3)}$ where three countings were done both during and after the sampling period. We call a radon daughter monitor based on the decay method a D.R.D. monitor and based on the build-up and decay method, a B.D.R.D monitor. From theoretical points of view, the B.D.R.D. monitor is expected to have significantly better precision, particularly in the measurement of RaA; in the gross counting way, it is very difficult to accurately measure the corcentration of the nuclide which has the shortest life time (3.05 minutes) among the daughters. On the other hand, the B.D.R.D. monitor may have some disadvantages from the practical viewpoints. For example, in the monitor of this type, the sampling and counting processes have to be performed in the same time and in the same part of the monitor. Consequently, the geometry of the sampling head of the instrument inevitably becomes complex. The complex geometry of sampling head may lead to substantial errors caused by deposition of radon daughters on the inner surface of the sampling head. Thus, we have to take into account of the other errors except for statistical errors in the evaluation of measuring method. Moreover, it is difficult to estimate overall errors from only the theoretical viewpoints. Therefore, we will actually make radon daughter monitors having different measuring principle, and make a decision of the most useful instrument for monitoring the concentrations of individual radon daughters indoors and outdoors.

We have reported about a D.R.D. monitor with a decay method. ${ }^{\text {) }}$ In this paper, we will perform an application of a B.D.R.D. monitor with a build-up and decay method and discuss the comparative merits of both monitors in as-

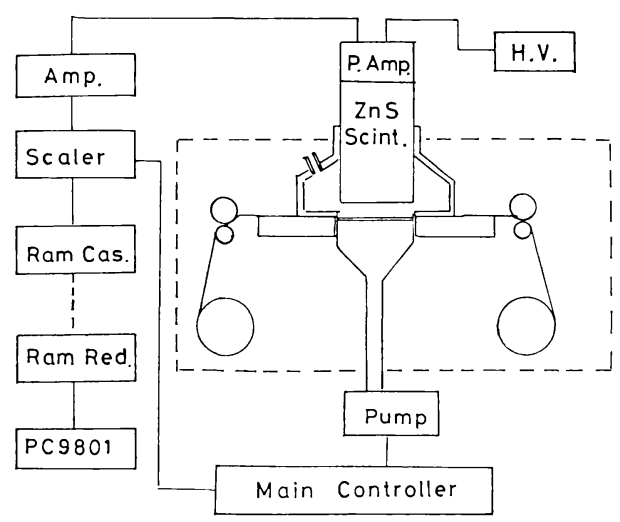

Fig. 1 The schematic of the operation of radon daughter monitor buildup-decay method (B.D.R.D. monitor).

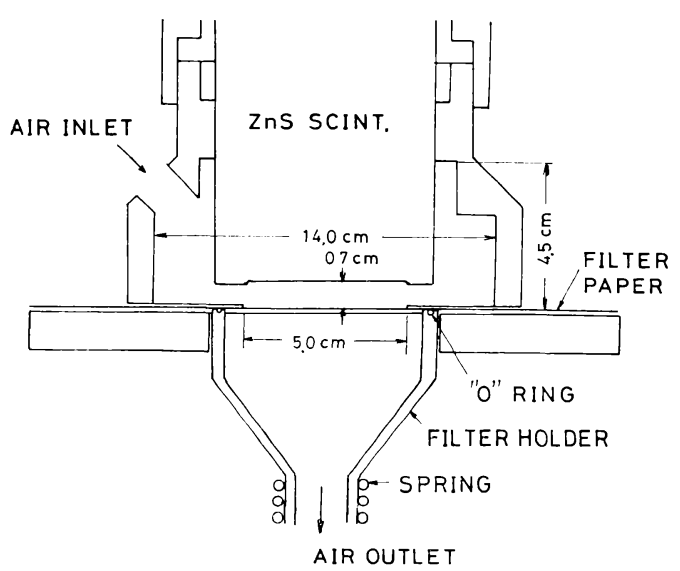

Fig. 2 The detailed design of the sampling head in B.D.R.D. monitor.

sessment of individual radon daughter concentrations.

\section{APPARATUS}

In Fig. 1, the schematic of a B.D.R.D. monitor is shown. It consists of a scintillation counter, a timer-scaller, an air pump, filter tape winders and a RAM cassette. Figure 2 shows the detailed design of the sampling head of the monitor. The design aims at providing a useful geometry for an air tightness and a simplification of structure.

In order to make the system operator-free, we use automatic motorized winders with a returning mechanism to move a filter tape regularly. The filter tape is a membrane filter $(0.8 \mu \mathrm{m}$ in pore size) with $60 \mathrm{~mm}$ in width and $10 \mathrm{~m}$ in length. Sampling air is drawn through an active spot (50 
$\mathrm{mm}$ in diameter) on the filter tape. The scintillation counter $(\mathrm{ZnS}(\mathrm{Ag}), 2$ inches in diameter) for alpha counting is mounted near the tape surface at a distance of $7 \mathrm{~mm}$. Output signals from the detector are transferred to the timer-scaller and the data are stored temporarily in a compact RAM cassette. Data of the RAM casette are fed into a microcomputer through a RAM cassette reader to calculate individual radon daughter concentrations.

In the present measuring system, the first one among the three countings is done for $T_{1} \mathrm{~min}$ while the sampling is being practiced. After a pause of $t$ seconds, the second and the third countings are done in succession for $T_{2}$ and $T_{3}$ each while the sampling is stopped. All operations complete one measurement cycle in $60 \mathrm{~min}$. A sending interval of the filter is $70 \mathrm{~mm}$. Therefore, the filter tape with a length of $10 \mathrm{~m}$ is turned over every 5 days by the returning mechanism. We change the filter tape every 2 months by considering the loading by particulate matters on filter. Thus, for maintenance of long term measurements, it is necessary to renew a RAM cassette every month and a filter tape every other month for this instrument.

\section{THE PRECISION OF THE RADON DAUGHTER MONITOR}

The precision of individual radon daughter concentration obtained with B.D.R.D. monitor may be dependent on operation conditions like scheme of three counting periods, flow rate and

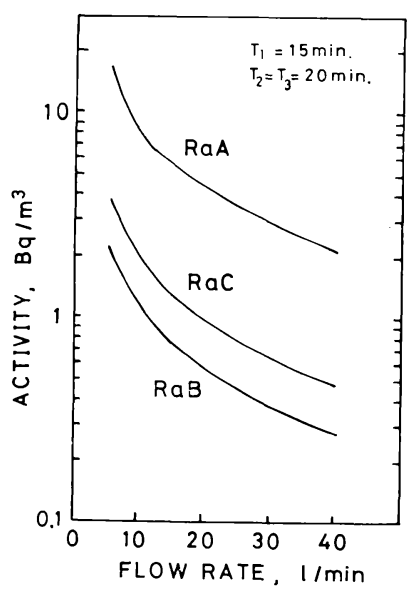

Fig. 3 Sensitivity for radon daughters as a function of flow rate.

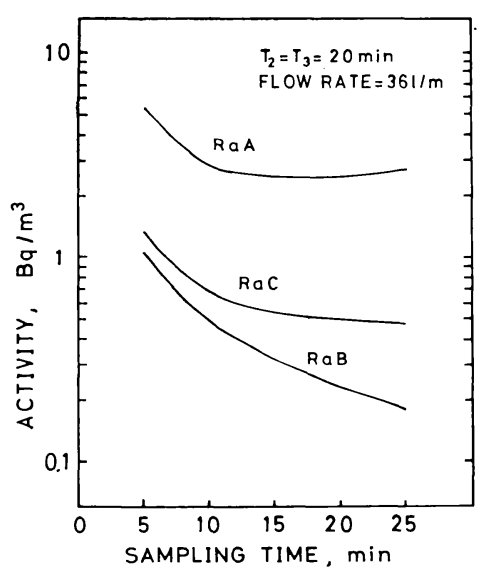

Fig. 4 Sensitivity for radon daughters as a function of sampling time.

so on. In order to optimize the operation conditions, statistical errors were calculated based on the method developed by Thomas. In Figs. 3 and 4, we show the calculation results of the sensitivities obtained as a function of flow rate or sampling time, where the sensitivities in these figures are indicated by the concentration having a relative standard deviation of 50 percent and the values of parameters used in the calculation are shown in the figures.

From Fig. 3, it is found that the increase of the flow rate contributes to enhancement of sensitivity of all radioactive nuclides. The sensitivities for $\mathrm{RaA}$ assessment are several times lower than that for $\mathrm{RaB}$ and $\mathrm{RaC}$. Also, the expansion of sampling time has the same effect as the increase of flow rate (Fig. 4). In regard to RaA of short half life, however, it is not effective for increasing the sensitivity to expand sampling time more than about $15 \mathrm{~min}$. The other parameters like the total counting time $\left(T_{1}+T_{2}+T_{3}\right)$ and the waiting time $(t)$ whose parameters are important in a D.R.D. monitor are insignificant, although the results are not shown in the figures. Also, the degree of unequilibrium between radon daughters depends slightly on the sensitivity. Based on these calculation results, we have selected the following values as parameters of this measuring system; $T_{1}=15 \mathrm{~min}$ and $T_{2}=T_{3}=20 \mathrm{~min}$.

\section{COMPARISON OF CHARACTERIS- TICS BETWEEN A D.R.D. MONITOR AND A B.D.R.D. MONITOR}

In order to know the characteristics of the 
monitors, we experimentally carried out comparison of sensitivities between radon daughter monitors of two types. The sampling and waiting time periods in the D.R.D. monitor were 10 min and $10 \mathrm{~s}$ respectively, as used previously. The three counting scheme was 4-27 min. Both monitors were used with the same flow rate of $36 \mathrm{l} / \mathrm{m}$. The measurements were performed for the period of 2 weeks in a house.

The hourly data from the both monitors were classified as 6 groups on the basis of the radon concentrations measured simultaneously and standard deviations of each group were calculated. In Fig. 5(A), (B) and (C), we show the experimental values obtained for each radioactive nuclide, together with theoretical values. The concentrations in the figure show the mean values of data in each group. In this case, the experimental values of the standard deviation include components of dispersion of data attributed to the concentration interval by the classification of the data and to the dispersion of data of radon concentrations used as a reference standard, except for the dispersion of data attributed to the radon daughter monitors. Therefore, in comparison between the theoretical and experimental values, it should be taken into consideration that the experimental values show somewhat large ones than the statistical errors of the instruments.

It is found from Fig. 5 that experimental results closely agree with the theoretical ones taking into account the overestimation of experimental values, described above. The standard deviations of $\mathrm{RaA}$ in the B.D.R.D. monitor are much smaller than those in the D.R.D. monitor. On the other hand, with regard to RaB, the values of the B.D.R.D. monitor are slightly larger than those in the D.R.D. monitor and the difference between standard deviations of $\mathrm{RaC}$ in both monitors is indistinguishable. Thus, from the experimental point of view, we can say that the radon daughter monitor with the build-up and decay method is much better than that with the decay method in assessment of RaA having short life time. Since precision of $\mathrm{RaA}$ is always insufficient in measurement of concentration of three radioactive nuclides, the result will give very important implication.

As described previously, a B.D.R.D. monitor is excellent one from standpoint of the statistical errors. However, we have to pay sufficient
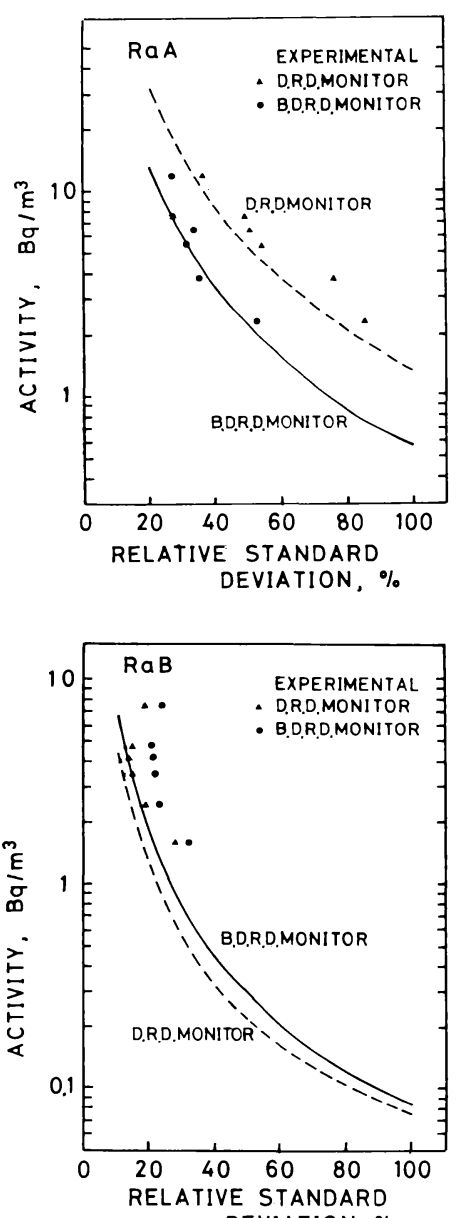

DEVIATION, \%

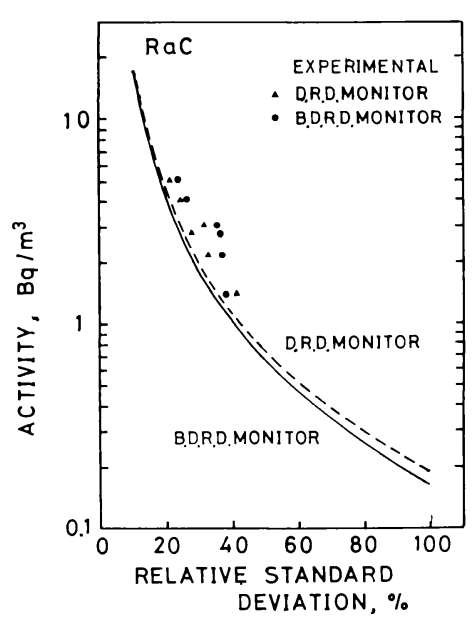

Fig. 5 Comparison of the sensitivity between B.D.R.D. monitor and D.R.D. monitor. In the figures, solid and dotted lines indicate theoretical values. 
attention for the disadvantages inherent in the monitor. As shown in Fig. 2, the sampling head of the B.D.R.D. monitor has intricate structures. Therefore, during the sampling of radon daughters, some of radon daughters, particularly unattached radon daughters, which do not attach to aerosol particles, may attach to the inner walls of the sampling head of the monitor. The plateout effect reduces the radon daughters collected on a filter and will lead to the underestimation of measured values.

In order to estimate the errors caused by the plateout to the monitor, we carried out the experiments by the following procedures: radon daughters were sampled on a wire screen (500 mesh), instead of a filter paper mounted in the B.D.R.D. monitor. It is possible that the sampling device with the wire screen actually collects only the unattached daughters by a diffusion process. Also, as a reference standard, unattached daughters were collected on the wire screen in a filter holder with the sampling inlet of open face, where the manual instrument will have negligible effect on the plateout. Both instruments were simultaneously operated under the same conditions in sampling time and counting time. From the experiments of the plateout of unattached daughters to instruments, the ratios of the counting values of the B.D.R.D. monitor to these of the reference instrument were calculated. The values were $0.78 \pm 0.07$ at the flow rate of $25 \mathrm{l} / \mathrm{m}$ and $0.82 \pm 0.10$ at that of $35 \mathrm{l} / \mathrm{m}$. From the comparison, it was found that about 20 percent of unattached daughters were removed by the plateout; the values are, of course, effective only for our instrument. However, the sampling part of the instrument was designed in such a way that the structure leads to the smallest effect of plateout. Therefore, the loss of about 20 percent of unattached daughters will be unavoidable in the instrument of this type. In the measurement of total radon daughters in usual environment, however, the loss may be insignificant because the fraction of unattached one to total radon daughter concentration is slight.

Another disadvantage of the B.D.R.D. monitor may be a rise in background count level caused from the long term measurement. In our monitor, two factors may contribute to the increase of the background level. One factor is due to repeated use of the filter tape. A filter tape is

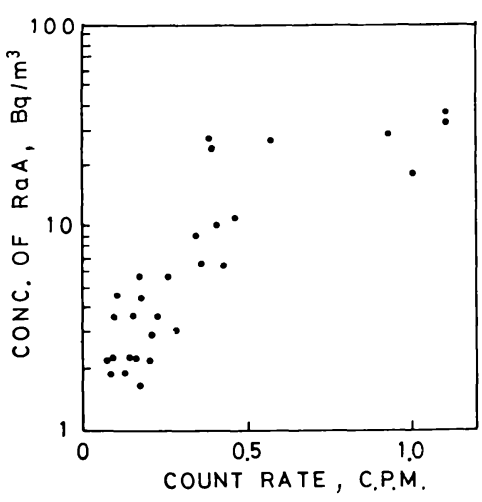

Fig. 6 The relation between the counting rate of background for the time interval of $55 \mathrm{~min}$ and the concentration of $\mathrm{RaA}$ in the air before $1 \mathrm{~h}$ the measurement of background.

repeatedly used with a cycle of 5 days for a period of 2 months. Activities of the long term radioactive nuclides like ThB and ThC are accumulated on the filter tape and the background levels may be enhanced. To estimate the enhancement of background level, the measurements under usual operation conditions were lasted during the periods of 2 months and after that, the background values of the filter tape were counted by the other radon monitor to distinguish from another effect in enhancement of background level. For measurements of 6 times including both indoor and outdoor airs, it was found that the background counts raised from $0.08 \pm 0.03$ to $0.15 \pm 0.05 \mathrm{cpm}$ for time interval of $55 \mathrm{~min}$. From the results, the enhancement of background values was not more than 2 times in the environment in which we performed. Therefore, the effect of accumulation of long life radioactive nuclides was insignificant.

The other factor enhancing background level is due to the accumulation of radon daughters to the inner walls of sampling parts of the monitor. A part of radioactive nuclides collected on the other inner surface, except for those on the filter paper may contribute to enhancement of background values. In order to estimate the enhancement of background values caused by the plateout effect, we performed measurements as follows; after the monitor was operated for several days under normal conditions, only the air pump was stopped. The measurements under no flow rate were lasted for a few hours. Figure 6 shows the relation between the counting rate of background 
and the concentration of $\mathrm{RaA}$ in the air measured before one hour the measurement of background. From the results, it is considered that the enhancement of background level depends on the concentration of radioactivity in the air in spite of wide scatter of data. It is found from Fig. 6 that the background count at the level of $30 \mathrm{~Bq} / \mathrm{m}^{3}$ in air radioactivity is about ten times the value at 5 $\mathrm{Bq} / \mathrm{m}^{3}$. If the concentration of radioactivity is assumed to be constant, the influence on the measured values of RaA by the enhancement of background level will be only contribution of a few percent and the error is very slight. However, its influence will become significant when the concentration of radioactivity in the air rapidly decreases.

\section{CONCLUSIONS}

Application of a build-up and decay method to radon daughter monitors for long term continuous measurements was carried out. The sensitivities of a B.D.R.D. monitor were experimentally compared with those of a D.R.D. monitor. From the point of the statistical errors, experimental results showed that the B.D.R.D. monitor was much better than the D.R.D. monitor in the assessment of RaA, as it was expected from theoretical results.

The monitor had unavoidable disadvantages. A sampling part of the monitor having intricate structures resulted in the loss of unattached radon daughters by the plateout process. The effect becomes insignificant if the fraction of unattached ones to total radon daughters is smaller than about 20 percent, ${ }^{5)}$ which are often measured. However, the underestimation in the assessment will be more than 10 percent in such extreme conditions $^{6}$ ) that the fraction of the unattached to total radon daughters is more than 50 percent.
Also, the plateout effect contributed to the enhancement of background counts. The enhancement depended on the concentration of radon daughter in the air existing before the measurement of background. It will lead to some errors in the case of sudden decrease of the concentration in the air.

From the results of overall comparison, the radon daughter monitor with build-up and decay method has an excellent advantage in the sensitivity of measurement of RaA. In our monitor, the concentration of $\mathrm{RaA}$ with a relative standard deviation of 50 percent is 2 to $3 \mathrm{~Bq} / \mathrm{m}^{3}$. The monitor is very useful one to measure individual radon daughters in the environment of low concentration. In the analysis of data, however, we always should take notice of disadvantages of the monitor.

\section{REFERENCES}

1) E. C. Tsivoglou, H. E. Ayer and D. A. Holady; Occurrence of nonequilibrium atmospheric mixtures of radon and its daughters, Nucleonics, 11, 40 (1953).

2) J. W. Thомаs; Measurement of radon daughters in air, Health Phys., 23, 783 (1972).

3) K. D. Cliff; The measurement of low concentrations of radon-222 daughters in air, with emphasis on RaA assessment, Phys. Med. Biol., 23, 55 (1978).

4) H. KoJima and S. ABE; An apparatus for environmental monitoring of short lived radon daughters, Hobutsu, 21, 167 (1986).

5) UNSCEAR, Ionizing Radiation; Sources and Biological Effects, United Nations, New York (1982).

6) M. Shimo and Y. IKeBE; Measurements of radon and its short-lived decay products and unattached fraction in air, Rad. Prot. Dos., 8, 209 (1984). 